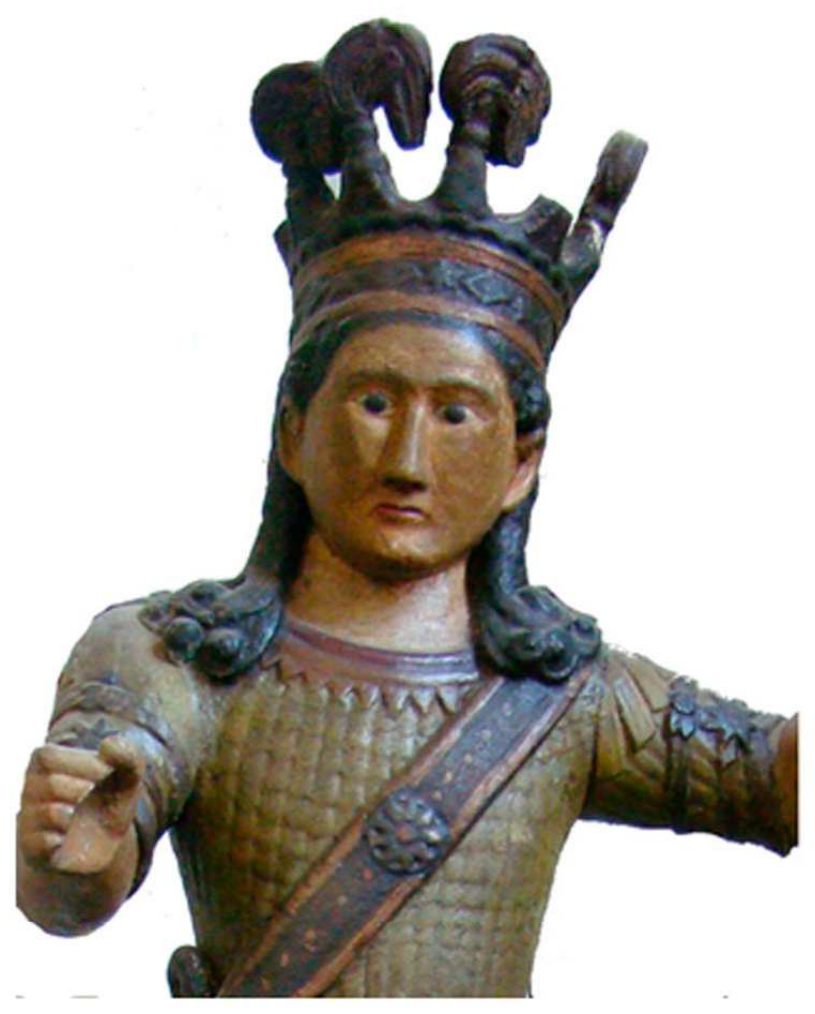

Imagem de São Miguel Arcanjo com cocar. $103 \mathrm{~cm} \times 49 \mathrm{~cm}$. Acervo: Museu Gaúcho da Força Expedicionária Brasileira (FEB). São Gabriel/RS. Fotografia de Jacqueline Ahlert

IMAGINÁRIA MISSIONEIRA:

REPRESENTAÇÕES DE UM PROCESSO HISTÓRICO COMPLEXO

\section{Jacqueline Ahlert}

Doutora em História Ibero-americana pela Pontifícia Universidade Católica do Rio Grande do Sul. Possui graduação em Artes Plásticas, habilitação em Educação Artística pela Universidade de Passo Fundo (2004) e mestrado em História pela Universidade de Passo Fundo (2007). Professora do Programa de Pós-Graduação em História (PPGH Me-Do) do Instituto de Filosofia e Ciências Humanas e da Faculdade de Artes e Comunicação - UPF. Pesquisadora do Programa de Pesquisas Interdisciplinares da Região Platina Oriental, que recebe apoio do CNPq e da PUCRS, e pesquisadora-responsável pelo inventário do acervo de estatuária missioneira e colonial, do Laboratório de Cultura Material e Arqueologia (LACUMA) - PPGH-UPF. 
AHLERT, Jacqueline. Imaginária missioneira: representações de um processo histórico complexo. Domínios da Imagem, Londrina, v. 9, n. 17, p. 65-85, jan./jun. 2015.

ISSN 2237-9126

Recebido em 16/03/2015 e aprovado em 17/06/2015.

Resumo: As imagens da Virgem, de Jesus, dos anjos e santos estavam presentes no amplo domínio físico-geográfico das doutrinas jesuíticasindígenas da Província do Paraguai. Gradualmente, no decorrer do processo de ressignificação dos preceitos e da iconografia cristã - num plano de mediações interculturais -, as representações adentraram a práxis religiosa dos missioneiros. Assimilações que se deram com base na construção de significados ao longo da formação de uma "cultura religiosa missional", num complexo trabalho de tradução mútua e de reorganização de elementos simbólicos. Deste modo, este texto, inicialmente, apresenta o espaço missional em que se movimentaram e articularam as imagens religiosas, para, posteriormente, expor aspectos de sua produção, usos e sentidos.

Palavras-chave: Missões Jesuíticas da Província Paraguaia, representações imagéticas, ressignificação.

Abstract: The images of the Virgin, Jesus, the angels and saints were present in the large physical and geographical domain of Jesuit-indigenous doctrines of the Province of Paraguay. Gradually, during the resignification process and the precepts of christian iconography - an intercultural mediation plan -, the representations stepped into the religious practice of the missionary. Assimilations that occurred based on the construction along the meanings formation of a "missional religious culture", in a complex mutual translation work and reorganization of symbolic elements. Thus, this text, initially, presents the missional space, which moved and articulated religious images, to subsequently, expose aspects of their production, uses and meanings.

Keywords: Jesuit Missions of Paraguay Province, imagistic representations, resignification.

\section{Introdução}

A constituição da Província Jesuítica do Paraguai deu-se em 1604, tendo como uma das principais intenções a formação de organizações missionais estáveis, em prol das missões volantes. A partir das projeções da Companhia de Jesus, apoiada pelo Estado moderno espanhol, a instalação de doutrinas iniciou-se em 1609, com a fundação de San Ignácio Guaçu. A fase inicial abrangeu a região do Guairá, ocupando, em seguida, o Itatim e prolongando-se até o Tape. Posteriormente, adentrando o século XVIII, consolidaram-se os Trinta Povos em território, atualmente, argentino, 
AHLERT, Jacqueline. Imaginária missioneira: representações de um processo histórico complexo. Domínios da Imagem, Londrina, v. 9, n. 17, p. 65-85, jan./jun. 2015.

ISSN 2237-9126

paraguaio e brasileiro, estendendo-se o alcance de algumas estâncias até o Uruguai.

Sob a tutela dos inacianos, as missões alcançaram 159 anos de duração, até a expulsão da Ordem da América espanhola, em 1768. Estiveram inseridas no contexto de um longo processo histórico, dinâmico, negociativo e mediado pela assimilação de novas cosmovisões, em que o indígena atuou como agente e coautor de soluções originais advindas das demandas que o processo missional apresentava. Longe de resumir-se à recepção unilateral por parte da cultura autóctone, ${ }^{1}$ a construção dessa sociabilidade se deu a partir de combinações singulares planeadas e elaboradas ao longo dos anos, com rupturas e continuidades após a saída forçada dos loyolistas. Assim, a percepção através de conceitos como de ressignificação, tradução, circularidade, amplia o entendimento dos processos culturais que envolveram os indígenas nas reduções.

As representações imagéticas advindas desta trama são tão complexas quanto a conjuntura que as engendrou. O que era a imaginária missioneira? Do que se compôs? (Do que se compõe?) E qual foi a amplitude de elementos que cingiu? Dessas questões, delineia-se a construção desse artigo, organizado de modo a, primeiramente, apresentar - espaço no qual se movimentaram as imagens religiosas, para, posteriormente, expor aspectos de sua produção, usos e sentidos. Tais considerações estão alicerçadas na conjectura de que, para além das visões caricaturais, da cenografia barroca, a imaginária missioneira foi construída pelo imaginário indígena², fosse nas esculturas, gravados, pinturas,

\footnotetext{
1 O termo autóctone é utilizado para designar os "habitantes primeiros do local referido em um tempo de longa duração" e não no sentido de "aquele que é natural de uma dada região", considerando que a povoação da América se deu através de correntes migratórias, sendo os indígenas emigrantes e não naturais destes locais.

2 Durand considera o imaginário o conjunto das imagens e relações de imagens que constitui o capital pensado do homo sapiens: "Finalmente o imaginário não é outra coisa que este trajeto no qual a representação do objeto se deixa assimilar e modelar pelos imperativos pulsionais do sujeito, e no qual, como magistralmente Piaget mostrou, as representações subjetivas explicam-se reciprocamente 'pelas acomodações anteriores do sujeito' ao meio objetivo" (DURAND, 1997. p. 18; 38; 41).
} 
AHLERT, Jacqueline. Imaginária missioneira: representações de um processo histórico complexo. Domínios da Imagem, Londrina, v. 9, n. 17, p. 65-85, jan./jun. 2015.

ISSN 2237-9126

escrita e arquitetura, na relação com as divindades, fosse na imaterialidade das festas, músicas, teatralidades e estetização das práticas religiosas.

\section{A espacialidade}

A espacialidade das doutrinas jesuíticas da Província Paraguaia, como espaços politicamente ordenados e culturalmente homogêneos, tem sido problematizada sob vários aspectos. Seja naquilo que se refere a composição étnica dos pueblos ${ }^{3}$, na dinâmica de suas extensões administrativas e econômicas, na participação indígena da estruturação urbana e construção dos edifícios, entre outros. De modo geral, são proposições que expõem uma participação efetiva dos missioneiros no processo, definido por Wilde (2009) como "agência" ou "autonomia indígena".

Falar de autonomia indígena no contexto missional não significa simplesmente aceitar que os índios foram capazes de atuar por si mesmos com base em escolhas racionais, o que resulta algo trivial e simplista a luz da literatura recente. Sobre tudo implica reconhecer que os indígenas desenvolvem noções e lógicas inspiradas em tradições e memórias sedimentadas (anteriores e posteriores ao contato com os europeus), as quais codificam noções singulares e dinâmicas de tempo, espaço e pessoa. Essas lógicas indígenas estão longe de ser manifestações de uma "pureza étnica". São o resultado de um processo de etnogênesis no qual "o indígena", ainda que apareça ocupando um lugar especial no discurso nativo e institucional, não constitui uma identidade unívoca, senão uma confluência de níveis e trajetórias inscritas social e historicamente (WILDE, 2009, p. 37).

\footnotetext{
3 Apesar da denominação usual de "Los Treinta Pueblos Misioneros Guaraníes", para o conjunto das reduções, havia também outras etnias indígenas inseridas no processo missional. A população das reduções contava com uma maioria de índios guaranis, embora existisse uma diversificação entre eles. No território onde atuaram os missionários encontravam-se, por exemplo, os Tayaobás, Guayaki, Tapes, entre outros que são classificados como Guarani pela historiografia (SANTOS; BAPTISTA, 2007, p. 241). Estes grupos compunham, minoritariamente, uma parcialidade da diversidade cultural no desenvolvimento e complexidade dos espaços reducionais.
} 
AHLERT, Jacqueline. Imaginária missioneira: representações de um processo histórico complexo. Domínios da Imagem, Londrina, v. 9, n. 17, p. 65-85, jan./jun. 2015.

ISSN 2237-9126

Entre os primeiros procedimentos para a instalação de um pueblo, estavam os de persuadir os caciques e organizar as parcialidades, estruturas organizativas que se manteriam no interior da doutrina. Levava-se a cabo, então, a alteração dos aldeamentos guaranis - caracterizados por amplos territórios com limites difusos, compostos de casas-habitação relacionadas ao terreiro/praça, a oka -, para os povoados missionais, que se formavam segundo um plano geométrico ordenado, em torno de uma grande praça quadrada. A "cristianização do índio deveria estar integrada à sua redução à polis, ou seja, à vida da cidade"; entretanto, adequada à tradição da ocupação do espaço da aldeia guarani (KERN, 2007, p. 7).

Materializados como uma composição cultural de influências europeias -medievais e modernas - e indígenas, os povoados missionais evoluíram estruturalmente através do tempo e da vivência. A configuração, cujas edificações eram de pedra e cobertas com telhas, ocorreu somente a partir do século XVIII, e não em todas reduções.

Independente dos condicionantes estilísticos, a execução das obras dependia inteiramente da mão-de-obra e dos conhecimentos indígenas, de modo que se conformou uma tipologia missioneira característica, elucidada pelo padre Cardiel, em 1747, a começar pela observação categórica de que, naquelas paragens, "todos esses edifícios se fazem de modo diverso aos da Europa". A edificação era iniciada, a maneira das malocas indígenas, pelo telhado - sustentado por troncos, chamados de horcones -, sendo as paredes erguidas posteriormente, sobre as fundações de pedra, de "dois ou três palmos acima da terra". Ainda que a pedra fosse abundante, a qualidade era arenito ou pedra-ferro, imprópria para cal. Para branquear as paredes, o método não era menos adaptado às condições que os outros: "fazemos cal suficiente de caracóis grandes, que em todas as partes se acham alguns. Manda-se as mulheres que os encontrem quando vão e voltam de suas roças". Os caracóis eram aquecidos intercalados com carvão, base inicial à qual se punha fogo; "em poucas horas se queima 
AHLERT, Jacqueline. Imaginária missioneira: representações de um processo histórico complexo. Domínios da Imagem, Londrina, v. 9, n. 17, p. 65-85, jan./jun. 2015.

ISSN 2237-9126

tudo". Moendo-se estes caracóis queimados, misturando-os com água e cola a base de couro branco, obtinha-se um branco "esplêndido" (Cardiel em FURLONG, [1747] 1953, p. 154-5).

Encontrar um critério de ordenação intrínseco a estas obras que as emancipe das, frequentemente, estéreis referências comparativas aos estilos europeus - ainda que indispensáveis no caso do século XVIII -, é necessário para incluir a arquitetura no rol das manifestações do imaginário missioneiro, com soluções construídas dentro da historicidade do contexto.

A maior parte da produção das oficinas - no tocante às talhas, ornamentos, instrumentos musicais -, tinha como destino a igreja. Abóbodas pintadas, altares "muito grandes, cheios de talhas e dourados com arcos setoriais" compunham as estratégias persuasivas elaboradas pelos padres (AZARA, [1781] 1998, p. 239-40).

As igrejas possuíam de três a cinco naves e de cinco a sete altares cada uma, todos ornados com retábulos dourados que abrigavam esculturas de santos. As paredes, comumente, eram pintadas com passagens da vida de Cristo e cenas do Velho Testamento. No teto, explorava-se a técnica do trompe-l'oeil4, cuja noção de profundidade elevava ilusoriamente ao céu. Conforme Furlong, "todo o espaço não ocupado por altares estava coberto de pinturas ou telas de pincel requintado" (1962, p. 224).

Gonzalo Doblas, tenente-governador que chegou às Missões por volta de 1785, observou que "o primeiro que se apresenta à vista são os templos; estes, ainda que não guardem regularidade em sua arquitetura e sejam de pouca duração, são muy suntuosos e estão bem adornados interiormente de retábulos" (1836, p. 56).

\footnotetext{
4 Trompe-l'oeil é uma expressão francesa: "enganar o olho", usada principalmente em pintura e arquitetura, por meio de uma técnica artística que, com efeitos de perspectiva, cria uma ilusão ótica que sugere profundidades, volumes e formas que não existem realmente.
} 
AHLERT, Jacqueline. Imaginária missioneira: representações de um processo histórico complexo. Domínios da Imagem, Londrina, v. 9, n. 17, p. 65-85, jan./jun. 2015.

ISSN 2237-9126

Todas as ruas da doutrina convergiam à igreja, o único edifício vertical do povoado, o centro espiritual e material a acentuar o sentido transcendente do projeto missioneiro, constituindo o principal marco morfológico da redução. Conforme Kern, "na praça central, a igreja dominava o povo inteiro, simbolizando o predomínio da ideia religiosa sobre a comunidade e materializando a autoridade dos missionários sobre o conjunto das Missões" (1982, p. 128)

No entanto, é imprescindível considerar que a Igreja, enquanto edifício e instituição, não agia como definidora única do espaço sagrado. Este estava presente também na construção de um imaginário e de uma lógica de tempo e devoção afastados do que apreendiam diretamente os padres. Assim, a mobilidade das imagens (esculturas de uso pessoal, medalhas, estampas, agnus dei etc.) dentro do espaço missioneiro é entendida não somente como o alargamento de práticas religiosas, mas como a tradução e a ressignificação dessas práticas no cotidiano indígena.

O espaço missional é, comumente, reduzido a um sinônimo do "plano urbanístico reducional", ou seja, a disposição do sítio onde se construíram os edifícios principais. Ainda que o pueblo se apresentasse como ponto de referência - pois abrigava a igreja, as oficinas, o cabildo, a casa dos padres, as moradias, a hospedaria, o cotiguaçu, o cemitério etc. -, a abrangência territorial das missões compreendia, na área rural, estâncias, fazendas e ervais, ligados por caminhos interceptados por capelas. Nas imediações, havia fontes de água, hortas, hospitais, pedreiras, cárceres, entre outras instalações vinculadas a estrutura produtiva das doutrinas. As imagens estavam presentes em todos esses domínios, abrangiam desde a

\footnotetext{
5 A forma predominantemente retangular das plantas das igrejas missioneiras levou muitos historiadores a estabelecerem paralelos com a igreja de Gesú, em Roma, marco identificador da Companhia, vista como arquétipo nos projetos jesuíticos em todos os continentes, inclusive nas reduções da Província Jesuítica do Paraguai. Sobre este engano, Sustersic afirma que: "eles esquecem que a arquitetura é fundamentalmente ordenação e experiência do espaço, as plantas e elevações não são, neste caso, os elementos definidores do mesmo". E complementa: "a planta de uma igreja missioneira de três naves mostra pouca diferença com as basílicas paleocristãs. Porém, o espaço de uma e outra é inteiramente distinto" (SUSTERSIC, 2004, p. 38).
} 
AHLERT, Jacqueline. Imaginária missioneira: representações de um processo histórico complexo. Domínios da Imagem, Londrina, v. 9, n. 17, p. 65-85, jan./jun. 2015.

ISSN 2237-9126

composição de capelas, oratórios móveis, altares portáteis e ermidas até a utilização independente, situação em que sua presença estava cingida pela simbologia da companhia e proteção divinas.

Para além das grandes imagens, pintadas e esculpidas, que ornavam o interior e o exterior das igrejas, pequenas esculturas, com até $10 \mathrm{~cm}$ de altura, estampas e medalhas, possivelmente, respondiam a necessidades subjetivas e pessoais de amparo e compleição.

\section{A imaginária}

A escultura, a pintura, a arquitetura e a música, estão entre as principais manifestações que condensaram o amálgama das influências formadoras da sociedade missioneira, conformando a cristandade e o animismo num contexto de reorganização e de modificações parciais no espaço social, na projeção do imaginário e das práticas simbólicas. Como produtos de um desenrolar histórico, as produções artísticas estiveram relacionadas a elementos de imposição, interpretação, assimilação e resistência.

As doutrinas contavam com inúmeras oficinas: olaria, moinho, padaria, carpintaria, ferraria etc., que representavam uma diversidade de ofícios em grande parte conectados as técnicas ocidentais. Era o local de onde saíam as armas, as louças, os instrumentos musicais, os retábulos, oratórios, estátuas, pinturas, cestas, selas para os cavalos, tecidos, caldeirões, tachos, sinos, campainhas, cálices e castiçais. Enfim, quase tudo daquilo que requeria o povoado e as demandas de comercialização. O número de oficineiros variava conforme o tamanho do povoado, podendo ultrapassar os quarenta (AHLERT, 2012)6.

\footnotetext{
${ }^{6}$ Naturalmente, a maioria dos indivíduos envolvidos nessas atividades eram congregados. A participação em congregações era restrita aos principais índios do povoado, tanto homens quanto mulheres, regulares em suas confissões, assíduos às missas e demais sacramentos. Os
} 
AHLERT, Jacqueline. Imaginária missioneira: representações de um processo histórico complexo. Domínios da Imagem, Londrina, v. 9, n. 17, p. 65-85, jan./jun. 2015.

ISSN 2237-9126

A imaginária missioneira, bem como os demais elementos provindos das oficinas, era predominantemente anônima. As raras atribuições de obras que estão nos relatos de cronistas e algumas correspondências ânuas informam pinturas dos irmãos da Companhia, como Bernardo Rodríguez, autor de La Inmaculada, e de Luis Verger (MCA, [1615-1641] 1969, p. 77-8).7

A alguns trabalhos escultóricos foi conferida autoria ao padre Sepp, como o retábulo e algumas imagens da Virgem de Altoetting, uma imagem de São João Batista Menino e uma de São José. De atribuição imprecisa, a hipótese provém mais da tradição oral do que de análises estilísticas aprofundadas. Já, ao italiano José Brasanelli são conferidas inúmeras esculturas, proporcionando a conjectura de diferentes fases da estatuária missioneira a partir da sua atuação nas doutrinas, entre 1691 e 1728.

As pesquisas realizadas, principalmente por Sustercic Bozidar (2001), denotam a importância das obras e da influência artística exercida pelo escultor italiano. Segundo o autor, a partir de sua chegada nada do produzido nas Missões paraguaias foi alheio ao seu trabalho, ao seu ensino, ou sua influência. As obras remanescentes - identificadas a partir da escultura de São Francisco de Borja (fig. 1), de autoria reconhecida -, podem auxiliar na definição de uma periodização que comporta a produção realizada nos 30 Povos durante os 159 anos de administração jesuítica8.

congregados chegaram a ser $19 \%$ da população total de alguns povoados (MCA [16151641], 1969, p. 186).

7 Sobre a representação de São Carlos, escreveu-se em 1633: A imagem pintada pelo pincel do irmão Luis Verger foi colocada no altar pelos padres com muito gosto e alegria de todos, dizendo-lhes que aquela era a imagem do santo protetor do povo, que estava sempre diante de Deus, rogando por eles para que fossem bons e crescessem suas comidas e que a ele deveriam acudir quando necessitavam de algo, que ele rogaria a Deus por eles (MCA, [1615-1641] 1969, p. 77-8).

8 Os estudos de Josefina Plá (1975) indicam a existência de quatrocentas imagens esculpidas com a colaboração de Brasanelli. Sustersic menciona como reconhecidas quarenta imagens na publicação El "Insigne artífice" José Brasanelli: Su participación en la conformación de un nuevo lenguaje figurativo en las misiones jesuíticas-guaraníes (In: Aranda, 2001, p. 623-643). 
AHLERT, Jacqueline. Imaginária missioneira: representações de um processo histórico complexo. Domínios da Imagem, Londrina, v. 9, n. 17, p. 65-85, jan./jun. 2015.

ISSN 2237-9126

\section{Figura 1}

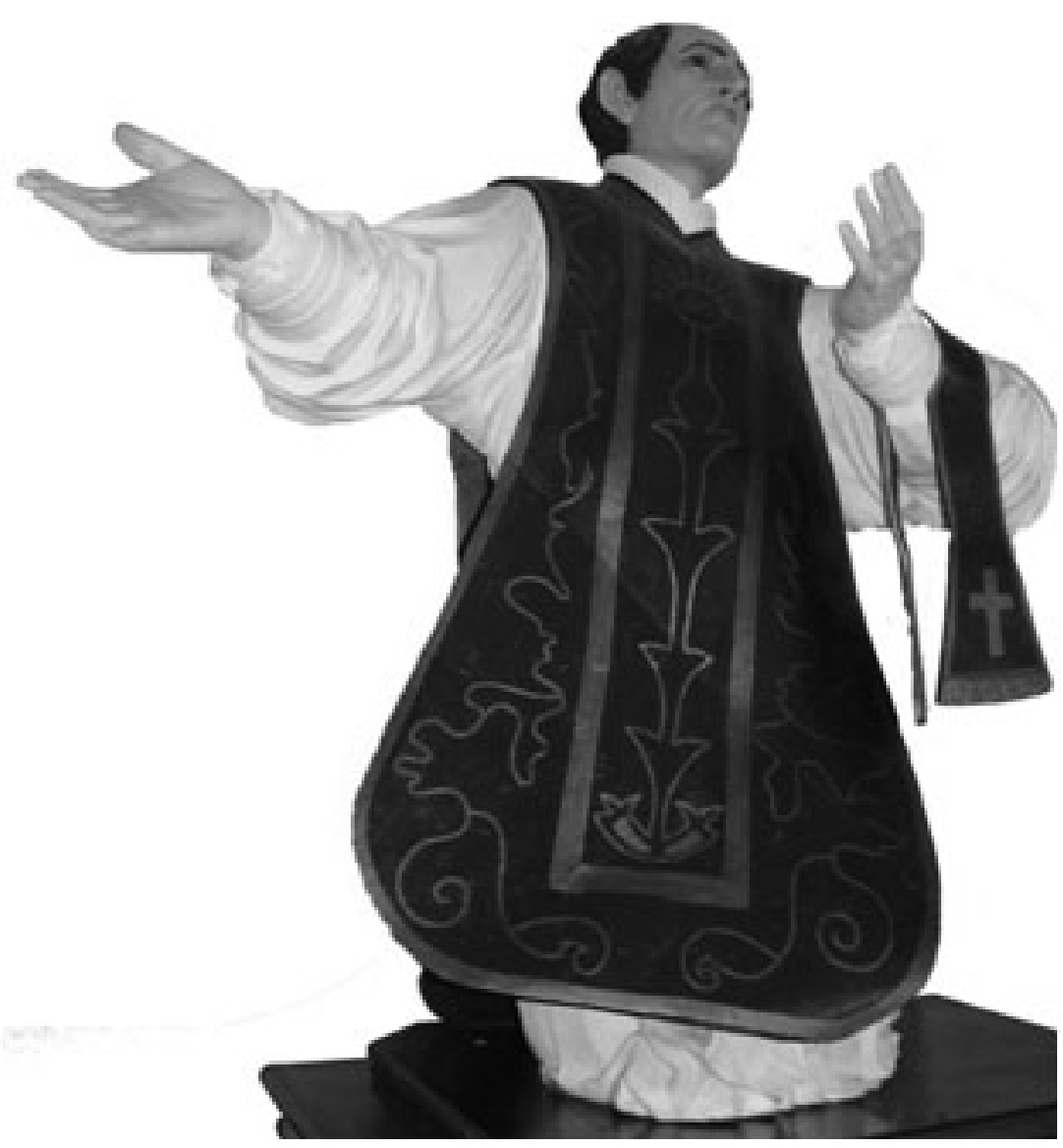

BRASANELLI, José. Imagem de São Francisco de Borja, $200 \mathrm{~cm}$ (aprox.). Matriz de São Borja/RS. Fotografia de Jacqueline Ahlert.

Para fins metodológicos, distinguiram-se quatro fases de produção. $\bigcirc$ primeiro período estendeu-se de 1610 a 1641. Foi marcado por viagens, fundações e guerras, podendo ser definido nas artes como o batismo da cultura vernácula. Fase em que se desenvolveu uma linguagem artística original, baseada em gravuras, de estatuas horcones, muito difundidas nas missões durante o século XVII.

Embora a produção artística missioneira recebesse, posteriormente, fortes influências dos estilos artísticos europeus, características como as de 
AHLERT, Jacqueline. Imaginária missioneira: representações de um processo histórico complexo. Domínios da Imagem, Londrina, v. 9, n. 17, p. 65-85, jan./jun. 2015.

ISSN 2237-9126

esquematismo, geometrismo, frontalismo e verticalidade, sobreviveram em maior ou menor medida na composição das estátuas. Este gesto se afirmou no resgate desta linguagem nos períodos seguidos a estas diretivas.

De 1641 a 1691 ocorreu uma fase de expansão e afirmação. Ela foi iniciada com a estabilidade propiciada pelas instalações definitivas depois do recuo dos bandeirantes, derrotados na batalha de Mbororé, em 1641, e com o acelerado crescimento demográfico. Nesse período, chegaram às oficinas missioneiras a influência do realismo castelhano e andaluz.

Entretanto, foi a introdução dos jesuítas centro-europeus, em 1691, que iniciou uma etapa de grandes mudanças artísticas nos povoados missioneiros, colocando em crise a escola escultórica do século XVII, que havia alcançado um notável estilo próprio. Essa reforma, primeiramente, questionou e rebateu a arte local e, gradualmente, foi se ajustando e se integrando a cultura indígena-missioneira. Este período prolongou-se de 1691 a 1728.

Estes aportes serviram de eixo para que no último período de produção dos talheres missioneiros (1730-1768) se desenvolvessem formas inéditas, onde os escultores guaranis, depois de Brasanelli, encontrariam uma identidade artística.

Depois deste momento, considerado o período clássico das manufaturas missioneiras, um quinto estágio prolongou-se após a expulsão dos jesuítas dos domínios espanhóis, constituído por imagens que combinam a memória das técnicas e iconografia jesuítica com o novo panteão de santidades das diferentes ordens religiosas que assumem os povoados missionais e, posteriormente, pela produção autônoma dos santeiros, desenvolvida, principalmente, no atual Paraguai. Esse último período já abrange uma nova imaginária, decorrente da circulação e construção de outro imaginário e de novas demandas.

A administração eclesiástica dos trinta povoados ficou sob responsabilidade de três ordens religiosas: Franciscana, Dominicana e 
AHLERT, Jacqueline. Imaginária missioneira: representações de um processo histórico complexo. Domínios da Imagem, Londrina, v. 9, n. 17, p. 65-85, jan./jun. 2015.

ISSN 2237-9126

Mercedária. Dificilmente, os novos curas se encarregaram com entusiasmo do projeto jesuítico e, certamente, não assumiram a didática dos inacianos. No Paraguai, logo após a saída dos jesuítas, grande parte dos artesãos, chamados mba'ekuaáva ("conhecedores de fazer bem as coisas", "qualificados") ou santo apoháva ("fazedores de santos"), abandonaram as reduções e se disseminaram pela Região Oriental, instalando-se às margens dos táva9 como "índios livres" (ESCOBAR, 2008, p. 32).

Em fins do século XVIII, encontravam-se funcionando poucas oficinas nos pueblos missioneiros. Houve, nesse momento, uma forte produção santeira realizada fora do formato reducional. Esta nova imaginária já estava contaminada pelo repertório iconográfico e estético das ordens religiosas introduzidas como substitutas dos loyolistas.

A conjectura de um estilo passível de classificação cronológica para estatuária missioneira não desconsidera a existência "paralela" de uma produção sobreposta, expressa, principalmente, nas imagens de uso particular, destituídas dos aparatos tradicionais da iconografia católica, dos excessos ornamentativos e apelos gestuais do estilo barroco.

Considerando a singularidade das soluções encontradas pelos maestros e artesões, constata-se que as obras produzidas pelos indígenas não constituíram meras réplicas das europeias. Apresentam originalidade na medida em que estão caracterizadas pela incorporação da identidade nativa aos modelos europeus transplantados. Tais criações demonstram a interatividade frente à catequização, ordenando e produzindo uma releitura dos símbolos, enredada nos significados da sua cultura e no momento pelo qual essa cultura passava.

\footnotetext{
${ }^{9}$ Táva significa cidade/núcleo de habitações em guarani.
} 
AHLERT, Jacqueline. Imaginária missioneira: representações de um processo histórico complexo. Domínios da Imagem, Londrina, v. 9, n. 17, p. 65-85, jan./jun. 2015.

ISSN 2237-9126

\section{Figura 2}

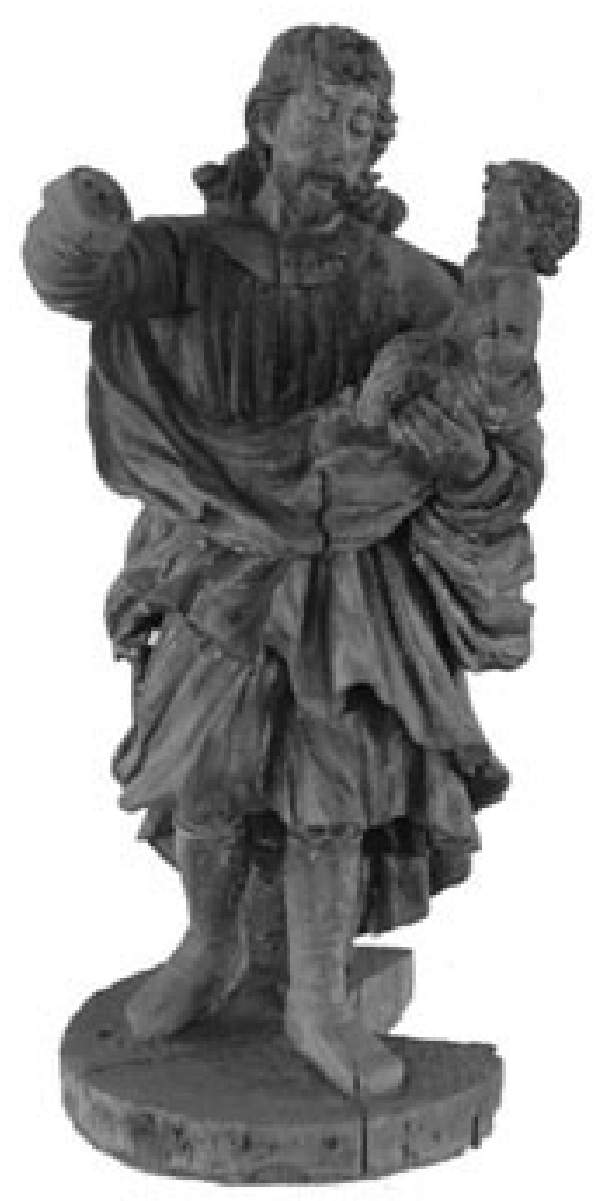

São José, $150 \mathrm{~cm} \times 85 \mathrm{~cm}$.

Acervo: Museu das Missões. São

Miguel/RS. Fotografia de Jacqueline Ahlert.
Figura 3

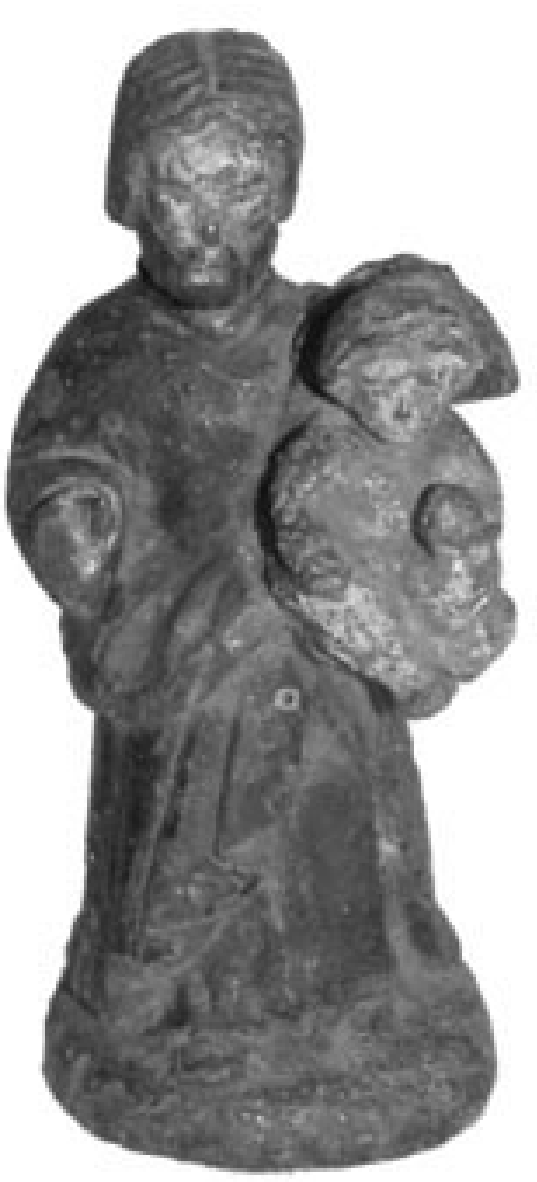

São José, $9 \mathrm{~cm} \times 4 \mathrm{~cm}$. Acervo: Museu Monsenhor Estanislau Wolski. Santo Antônio das Missões.

A diferença entre as representações é elucidativa da incorporação e hibridização iconográfica realizada pelos artesãos missioneiros.

Com a ressalva de que referir-se à interatividade, ou mesmo, a mediação e interculturalidade é certamente arriscado se tomado como uma realidade irrestrita. Já que estas terminologias, projetadas no contexto colonial, poderiam "correr o risco de apresentar uma imagem falsa de 
AHLERT, Jacqueline. Imaginária missioneira: representações de um processo histórico complexo. Domínios da Imagem, Londrina, v. 9, n. 17, p. 65-85, jan./jun. 2015.

"equilíbrio" cultural, que esconde as reais relações de força e as situações objetivas de opressão" (POMPA, 2012, p.103).

\section{Os usos e sentidos}

Tão amplos quanto o alcance das imagens no vasto domínio físico das Missões eram os usos, sentidos e as atribuições conferidas a elas. Perpassando poderes curativos, as representações dos personagens sagrados poderiam operar "verdadeiros milagres", segundo as narrativas dos padres.

\section{Figura 4}

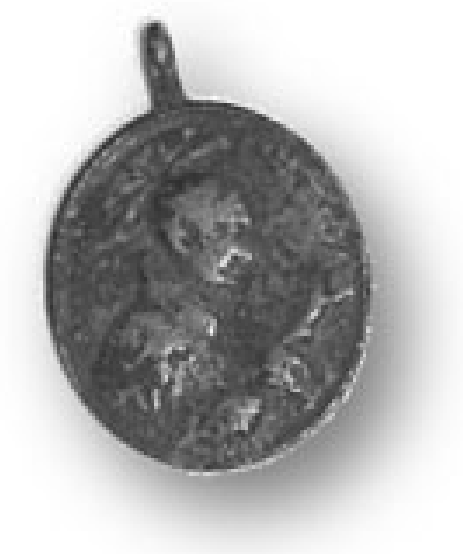

Medalha com relevo da imagem de Santo Inácio de Loyola. Acervo: Museo Histórico y Arqueológico Andrés Guacurarí. Posadas/ARG. Fotografia de Jacqueline Ahlert.

As pestes eram um grande pesadelo para os sacerdotes e neófitos. $\mathrm{Na}$ San Javier de 1760, a epidemia de varíola chegou a causar 14 mortes por dia, nos dois meses mais violentos. Havia oito índios responsáveis por abrir covas continuamente (Paucke em AUWEILER, [1748] 1900, p. 106-7). "Estas 
AHLERT, Jacqueline. Imaginária missioneira: representações de um processo histórico complexo. Domínios da Imagem, Londrina, v. 9, n. 17, p. 65-85, jan./jun. 2015.

ISSN 2237-9126

enfermidades têm enviado o Nosso Senhor por castigo aos pecados", justificavam, invariavelmente, os padres (MCA, [1615-1641] 1969, p. 178)10.

Nas tentativas de sanar tais males, o uso de medalhas (fig. 4), relíquias, estampas e de papéis com inscrições e bênçãos era largamente explorado. Certa feita, "uma cura milagrosa foi oferecida pelo Nosso Senhor por intercessão do santo padre Inácio, a uma criatura que estava agonizando". Bastou colocar "sobre o seu peito uma medalha do santo e pronunciar sobre ela as palavras do Evangelho [...] e logo estava, com admiração dos outros índios, perfeitamente sã" (MCA [1635-1637] 1990, p. 132).

Inácio de Loyola era, sobretudo, considerado o protetor das gestantes e dos partos. Na Redução de Corpus Christi, em 1660, sofria uma índia grávida com dores fortíssimas. Depois de haver se confessado, o padre "encomendou sua alma a São Inácio, deixando em seu colo a sua medalha". A índia "abraçou a medalha e beijou-a muitas vezes, com grande afeto". No dia seguinte, estando a mãe curada, teria nascido saudavelmente a criança abençoada pelo santo fundador da Companhia (MCA [1615-1641] 1969, p. 187).

Tais interseções não eram mediadas somente pelos padres, haja vista que havia, geralmente, somente dois sacerdotes para administração de cada povoado, com milhares de indígenas. Considerava-se a possibilidade de os indígenas congregados efetuarem tarefas de cunho espiritual bastante complexas, como a extrema-unção ou o batismo, além de portarem cédulas com imagens de santos e dessa forma distribuírem "milagres curativos" (MCA [1611-1758] 1970, p. 107)11.

\footnotetext{
10 As mortes ocasionadas pelas pestes (em especial sarampo e varíola) foram numerosas. Das 30.116 famílias existentes em fins de 1731, restaram no início de 1735 a cifra de 22.426, havendo 8.580 famílias extintas - 18\% a menos. Em outros números, das 139.244 pessoas, de todas as idades e ambos os sexos, restaram 107.549. Foram 31.695 pessoas desaparecidas dos povoados. Essa crise duraria mais quatro anos. De fato, da população de 144.252 indivíduos em 1732, restariam somente 74.159 em 1739. In: MCA- Centro Pesquisas Históricas da PUCRS. Cx. 22. Doc 27.

11 Sobre as congregações, ver: Jean Baptista (2009).
} 
AHLERT, Jacqueline. Imaginária missioneira: representações de um processo histórico complexo. Domínios da Imagem, Londrina, v. 9, n. 17, p. 65-85, jan./jun. 2015.

ISSN 2237-9126

A parafernália litúrgica imagética, barroca ou não, causou grande impacto na população nativa, e os padres não demoraram a se dar conta disso. Orientados pelos ditames das estratégias contrarreformistas ${ }^{12}$, utilizaram-se amplamente da imagem de Nossa Senhora da Conceição, a Virgem Conquistadora, e empolgaram os índios com o conjunto teatral, visual, sonora e sensitivamente. Esses artifícios satisfaziam o sentido realista dos autóctones, cuja mentalidade festiva compartilhava desse tipo de catequese lúdica.

Uma imagem da Virgem, prenda querida do santo Padre Roque, a qual havia sido companheira em suas peregrinações e que, colocada nalgum povo, depois de este se achar fundado, ele mesmo conduzia a outro. Assim, e com razão, chamava-a "a Conquistadora", atribuindo à sua presença os sucessos prósperos de suas empresas (MONTOYA, [1639] 1985, p. 200).

Ainda na segunda metade do sec XVIII, O estandarte de Nossa Senhora acompanhava os "caçadores" de infiéis nos montes. Junto com presentes dos missionários, o padre Paucke entregou aos índios que visitariam seus amigos a convite de se reduzirem, "uma bandeirinha branca que tinha de um lado a imagem de Nossa Senhora das Dores e do outro a de São Francisco Xavier, sinal pelo qual sempre poderiam ser identificados como índios cristãos" (em AUWEILER, [1748] 1900, p. 111).

A relação estabelecida com as imagens ia muito além daquela intercedida pelos padres. Imagens de médio porte 130 a $50 \mathrm{~cm}$, algumas podendo variar até a altura de $90 \mathrm{~cm}$ ) eram empregadas em capelas nas estâncias e chácaras, carregadas em andores nas procissões menores e cotidianas do povoado, como nas idas e vindas às áreas de cultivo e, possivelmente, nos altares principais do ambiente doméstico da família

\footnotetext{
12 A Ordem dos Jesuítas não foi a única criada na primeira metade do século XVI com o intuito de contribuir com o processo reformador da Igreja. Os Teatinos (1524), os Irmãos Menores Capuchinos (1528), os Samascos (1537) e os Barnabistas (1539) constituem-se em outras ordens religiosas que podem ser consideradas nascidas reformadas.
} 
AHLERT, Jacqueline. Imaginária missioneira: representações de um processo histórico complexo. Domínios da Imagem, Londrina, v. 9, n. 17, p. 65-85, jan./jun. 2015.

ISSN 2237-9126

extensa ${ }^{13}$. A esse conjunto pertencem as representações usadas para proteger os labores rurais (como as de São Roque e Santo Isidro) e acompanhar viagens e expedições militares (como São Miguel e São Rafael).

No amálgama que foi se construindo, as estátuas dos santos passaram a receber solicitações e oferendas ao modo de antigas práticas guaranis/indígenas. Em 1633, duas índias da redução de Nossa Senhora da Assunção de Acaragua, agradecidas pelo bom tempo que Nossa Senhora Ihes havia proporcionado para cultivar suas plantas, entraram na igreja para "visitar a santa e oferecer as primícias de seus frutos" (MCA [1615-1641] 1969, p. 68).

No mesmo ano, o padre da redução dos Santos Mártires de Caaró ${ }^{14}$, durante a noite, enquanto visitava os enfermos, deparou-se com uma casa que tinha "uma estampa de papel posta decentemente em uma mesa, iluminada por uma vela que haviam feito de cera, retirada do monte, todos da casa estavam de mãos postas diante da imagem e rezando alto as orações". Muito surpreso, o religioso alegrou-se diante de tal gesto, justificando que "era coisa rara e nunca vista nesta gente, que não é quase capaz de ter em suas casas e aposentos algumas imagens ou coisa semelhante". Para o padre, a ausência de imagens devia-se à precariedade das habitações. As casas assemelhavam-se a "currais de animais imundos" reclamava o religioso -, "cuidam somente de ter lenha para o fogo e milho para comer [...]. Como cama, usam um tipo de 'grelha' coberta por uma esteira. [...], e por este relaxamento e preguiça natural não têm atitude para ter em suas casas coisa alguma de devoção ou cristandade" (MCA [16151641] 1969, p. 73). No entanto, a prática estabelecer-se-ia na medida em

\footnotetext{
13 Nas ruínas da redução de San Ignácio/ARG, encontram-se nichos para oratórios nas paredes das casas dos índios. É importante destacar que este espaço de culto doméstico não é comum a todas as casas, o que conjectura a hipótese de que a imagem cultuada poderia pertencer à família extensa e não à elementar.

${ }^{14}$ A redução de Caaró situava-se na região chamada Uruguay, à margem esquerda do rio Uruguai.
} 
AHLERT, Jacqueline. Imaginária missioneira: representações de um processo histórico complexo. Domínios da Imagem, Londrina, v. 9, n. 17, p. 65-85, jan./jun. 2015.

ISSN 2237-9126

que os princípios teológicos católicos iam sendo eleitos, traduzidos e assimilados.

Talvez não compreendesse o padre que levar o culto para dentro das casas era parte de um complexo processo de interiorização e acomodação do novo panteão religioso, de ressignificação e reelaboração mítica. Ao passo que introduziam os santos em seus lares, faziam-no também em seus dogmas e este gesto se repetiria e se firmaria na práxis dos índios missioneiros, tornando-se insígnia de sua própria identidade. Mais de duzentos anos após a observação do padre de Caaró, La Gaceta Mercantil de Montevidéu notificava a presença de índios missioneiros na República do Uruguai, "que nada traziam, senão miséria e santinhos" de culto doméstico (LA GACETA MERCANTIL, 1830 apud FAVRE, 2009, p. 125).

Nos povoados, o hábito foi construído como tudo que tem sentido e historicidade. A fitoterapia milenar compartilhou domínios com imagens de santos. Desde Nossa Senhora de Loreto, a ânua de 1637 faz referência a um feiticeiro convertido que, em seu leito de morte, chamou ao cura e "tirou do peito uma bolsinha, onde mantinha algumas coisinhas de devoção [...], e entregou ao padre" (MCA [1615-1641] 1969, p. 203). Objetos apontados pelo clérigo como de "devoção" invariavelmente pertenciam ao orbe católico, do contrário, seriam manifestações do "demônio". Tal operação constituiu uma metamorfose cultural surpreendente. Xamãs acompanhados de suas ervas e representações de santos e da Virgem, continuavam a proferir as "palavras sagradas" e curativas sob o conhecimento dos padres jesuítas 15.

\footnotetext{
15 Nos primeiros anos, os jesuítas mantiveram a cautela na imposição de novas práticas, de modo que, tampouco falaram da pluralidade de mulheres, pois, "estando entre elas, tão válida era a honra e grandeza, que seria fazer odioso o evangelho tocar aspecto tão delicado" (ALVEAR, [1791] 1836, p. 42).
} 
AHLERT, Jacqueline. Imaginária missioneira: representações de um processo histórico complexo. Domínios da Imagem, Londrina, v. 9, n. 17, p. 65-85, jan./jun. 2015.

ISSN 2237-9126

\section{Considerações finais}

A língua, as imagens, os cultos, as práticas de um modo geral, não se estruturaram em um período breve, nem num único espaço, tanto menos verticalmente. Foi num contexto negociativo, protagonizado por escolhas indígenas, que se fixou a práxis do culto às imagens, sobretudo, no ambiente doméstico. Sem este fator, grande parte do esplendor das igrejas, das festividades, em suma, da cenografia barroquizante, perderia em sentido.

A fluidez da dinâmica missional estava caracterizada por conexões múltiplas, afiliações móveis, identidades heterogêneas, lealdades ambíguas, constituindo relações "alter-nativas" de espacialidade, temporalidade e memória. Afora a complexidade do fenômeno, a aproximação com as dinâmicas missionais só é possível através dos discursos que os atores produziram, condicionada pelas circunstâncias que foram elaboradas, muitas delas ignoradas. Posto que todo o discurso está condicionado por situações concretas de interação e possui destinatários. De onde um problema básico da interpretação seja a reconstrução da rede de interações e seu contexto (suas sedimentações ou tradições) que dão sentido ao conjunto de ações (WILDE, 2009).

A ideia de tradução pode contribuir para uma aproximação do processo de construção de um plano de mediação intercultural, no qual a alteridade encontra um sentido e um valor. O conceito aproxima-se do que Gruzinski chamou de "colonização do imaginário". Inclui a percepção e a devolução para o outro, da nova realidade colonial e missionária. Problematiza-se, assim, a "religião" como código de intercomunicação, "a pergunta relativa ao se e quanto os índios se converteram ao cristianismo é substituída pela pergunta relativa aos significados que a noção de conversão foi assumindo ao longo de séculos de missionação" (POMPA, 2012, p. 103). 
AHLERT, Jacqueline. Imaginária missioneira: representações de um processo histórico complexo. Domínios da Imagem, Londrina, v. 9, n. 17, p. 65-85, jan./jun. 2015.

ISSN 2237-9126

Neste sentido - com a ressalva de não almejar uma equivalência de influências religiosas e cosmológicas -, observa-se que os universos simbólicos indígena e jesuítico não se retraíram em busca de uma preservação de identidade, mas se abriram à absorção do outro e à sua própria transformação (POMPA, 2012).

As imagens, introduzidas por intermédio de um projeto ideológico unificador, centralizado na cristandade ocidental, ganharam lugar dentro da práxis, por que haviam sido constituídas de significados ancorados na ancestralidade dos sujeitos envolvidos, ao longo da construção de uma "cultura religiosa missional", num complexo e articulado trabalho de tradução reciproca e de organização simbólica.

\section{Referências}

AHLERT, Jacqueline. Estátuas andarilhas as miniaturas na imaginária missioneira: sentidos e remanescências. 2012. Tese (Doutorado) - Instituto de Filosofia e Ciências Humanas, PUCRS, Porto Alegre.

ALVEAR, Diego de. Relación geográfica e histórica de la provincia de Misiones. Buenos Aires: Imprenta del Estado, [1791] 1836 (Coleção de Angelis).

AUWEILER, Johann. Memorias del P. Florian Paucke: misionero de la compañia de Jesús 1748 a 1767. Buenos Aires: Imp. Encuad. y Estereotipia de L. Mirau, 1900.

AZARA, Félix de. Viajes por la America meridional. Tomo II. Buenos Aires: El Elefante Blanco, 1998.

BAPTISTA, Jean. Dossiês históricos do Museu das Missões: Volume Il: O eterno: crenças e práticas missionais. São Miguel das Missões: Museu das Missões, IBRAN, 2009.

DOBLAS, Gonzalo de. Memoria histórica, geográfica, política y económica sobre la provincia de Misiones de indios guaranis. Buenos Aires: Imprenta del estado, [1785] 1836.

DURAND, Gilbert. As estruturas antropológicas do imaginário. São Paulo: Martins Fontes, 1997. 
AHLERT, Jacqueline. Imaginária missioneira: representações de um processo histórico complexo. Domínios da Imagem, Londrina, v. 9, n. 17, p. 65-85, jan./jun. 2015.

ISSN 2237-9126

ESCOBAR. Santo e seña: acerca de las imaginería religiosa misionera y popular en el Paraguay. In: Catálogo Imaginería Religiosa. Asunción: Museo Del Barro, 2008.

FAVRE, Oscar Padrón. Ocaso de un pueblo indio: Historia del éxodo guaranímissionero al Uruguay. Durazno: Tierra a Dentro, 2009.

FURLONG, Guillermo S.J. José Cardiel S.J. y su Carta Relación (1747). Escritores Coloniales Rioplatenses II. Buenos Aires: Libraria del Plata, 1953.

FURLONG, Guillermo, S. J. Misiones y sus pueblos de guaraníes. Buenos Aires: Theoria, 1962.

KERN, Arno Alvarez. Missões, história e arqueologia: frentes de colonização, contatos interétnicos, intercâmbios culturais. 26ª Reunião da SBPH, 2007.

KERN, Arno Alvarez. Missões: uma utopia política. Porto Alegre: Mercado Aberto, 1982.

MANUSCRITOS DA COLEÇÃO DE ANGELIS. Jesuítas e bandeirantes no Uruguai (161 1-1758). Introdução, notas e sumário de Helio Vianna. Biblioteca Nacional: Divisão de Publicações e Divulgação, 1970.

MANUSCRITOS DA COLEÇÃO DE ANGELIS. Jesuítas e bandeirantes no Tape (1615-1641). Introdução, notas e sumário de Jaime Cortesão. Rio de Janeiro: Biblioteca Nacional, 1969.

MANUSCRITOS DA COLEÇÃO DE ANGELIS. Cartas ânuas de la provincia Jesuítica del Paraguay (1532 - 1634). Introdução de Ernesto J. A. Maeder. Buenos Aires: Academia Nacional de Historia, 1990.

MANUSCRITOS DA COLEÇÃO DE ANGELIS. Coleção micro-filmada. Centro de Pesquisa Histórica da PUCRS.

MONTOYA, Antônio Ruiz de. Conquista espiritual feita pelos religiosos da Companhia de Jesus nas províncias do Paraguay, Paraná, Uruguay e Tape. Porto Alegre: Martins Livreiro, [1639] 1985.

PLÁ. Josefina. El barroco hispano-guarani. Asunción: Editorial del Centenario S.R.L., 1975.

POMPA, Cristina. Religião como tradução: dizer mítico e fazer ritual na evangelização dos índios. In: RODRIGUES, Luiz Fernando Medeiros; HARRES, 
AHLERT, Jacqueline. Imaginária missioneira: representações de um processo histórico complexo. Domínios da Imagem, Londrina, v. 9, n. 17, p. 65-85, jan./jun. 2015.

ISSN 2237-9126

Marluza Marques (Orgs.) A experiência missioneira: território, cultura e identidade. São Leopoldo: Casa Leiria, 2012.

SANTOS, Maria Cristina dos; BAPTISTA, Jean Tiago. Reduções jesuíticas e povoados de índios: controvérsias sobre a população indígena (séc. XVIIXVIII). Revista História UNISINOS, v. 4, n. 2, jul./dez. 2000.

SUSTERCIC, Bozidar D. El "Insigne artífice" José Brasanelli. Su participación en la conformación de un nuevo lenguaje figurativo en las misiones jesuíticasguaraníes. In: ARANDA, A. M. (Eds.). Barroco iberoamericano. Territorio, arte, espacio y sociedad. Sevilla: Giralda, 2001. p. 623-643.

- Templos jesuítico-guaraníes: la historia secreta de sus fábricas y ensayos de interpretación de sus ruinas. Buenos Aires: Faculdad de Filosofía y Letras - UBA, 2004.

- El arte guaraní de las misiones jesuíticas y franciscanas en la Colección de Nicolás Darío Latourrette Bo. In: El barroco en el mundo guaraní. Asunción: Editorial del Centenario, 1975.

WILDE, Guillermo. Religión y poder en las misiones de guaraníes. Buenos Aires: SB, 2009. 